\title{
Presente y futuro de los estudios de Retórica, Argumentación y Discurso en América Latina*
}

\section{Entrevistada: María Alejandra Vitale}

Profesora Titular regular de la Universidad de Buenos Aires, Argentina orcid.org/0000-0002-2746-4070

En esta entrevista, exploramos la trayectoria académica de María Alejandra Vitale. Conversamos sobre su carrera universitaria y su formación intelectual, repasamos su participación en sociedades científicas de retórica, argumentación y discurso, y nos centramos en sus proyectos de investigación en la Universidad de Buenos Aires y en la Agencia Nacional de Promoción Científica y Tecnológica. Durante el intercambio, transitamos diversos temas de importancia social: la representación que la prensa nacional hizo de las últimas dictaduras argentinas, el estudio de los denominados "archivos de la represión", los discursos políticos y religiosos, con especial preocupación por la retórica de la "nueva" derecha. De la mirada sobre estos asuntos, es parte también una reflexión teórica-metodológica sobre nociones que nuestra entrevistada ha abordado con particular lucidez en las décadas recientes: la noción de memoria retórico-argumental, la relación entre ethos y kairos, el diálogo interdisciplinario entre retórica, argumentación, análisis del discurso y semiótica, entre otros.

Palabras clave: Alejandra Vitale. Argentina. Retórica. Argumentación. Discurso.

\section{Presente e futuro dos estudos de Retórica, Argumentação e Discurso na América Latina}

Nesta entrevista, exploramos a trajetória acadêmica de María Alejandra Vitale. Conversamos sobre sua carreira universitária e sua formação intelectual, sua participação em sociedades científicas de retórica, argumentação e discurso, bem como seus projetos de pesquisa na Universidade de Buenos Aires e na Agência Nacional de Promoção Científica e Tecnológica. Durante a interlocução, discutimos vários temas de importância social: a representação que a imprensa nacional fez das últimas ditaduras argentinas, o estudo dos chamados "arquivos da repressão", os discursos políticos e religiosos, com especial atenção à retórica da "nova" direita. Do olhar sobre essas questões, também faz parte uma reflexão teórico-metodológica sobre noções que a nossa entrevistada tem abordado com particular lucidez nas últimas décadas: a noção de memória retórico-argumentativa, a relação entre ethos e kairos, o diálogo interdisciplinar entre retórica, argumentação, análise do discurso e semiótica, entre outros.

Palavras-chave: Alejandra Vitale. Argentina. Retórica. Argumentação. Discurso.

\section{Present and future of the studies of Rhetoric, Argumentation and Discourse in Latin America}

In this interview, we explore the academic career of María Alejandra Vitale. We talked about her professional background and her education, as well as her participation in scientific societies of Rhetoric, Argumentation, and Discourse. We focused on her research projects at the University of Buenos Aires and at the National Agency for Scientific and Technological Promotion. Throughout the dialogue, we discussed various topics of social importance: the national press' representations of the last Argentine dictatorships, the study of the so-called "repression archives", the political and religious discourses, with special concern for the rhetoric of the "new" right. A theoretical-methodological reflection on notions that our interviewee has approached with lucidity in recent decades is also part of the gaze on these matters of public relevance: the notion of rhetorical-argumentative memory, the relationship between ethos and kairos, the interdisciplinary dialogue between Rhetoric, Argumentation, Discourse Analysis and Semiotics, among others.

Keywords: Alejandra Vitale. Argentine. Rhetoric. Argumentation. Discourse.

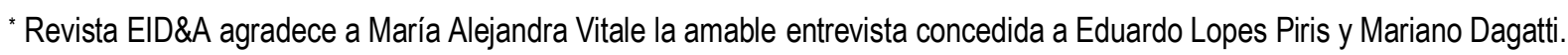


La Revista Eletrônica de Estudos Integrados em Discurso e Argumentação -EID\&Ainauguró su sección Entrevistas en agosto de 2021. Su propósito es dar a conocer el trabajo de investigadores e investigadoras que han contribuido a la consolidación del campo de pesquisa de la retórica, la argumentación y el discurso, sea en el ámbito nacional o internacional.

Comenzamos nuestro proyecto entrevistando al profesor e investigador portugués Rui Alexandre Grácio y, en este número, ofrecemos al lector una entrevista con la profesora e investigadora argentina María Alejandra Vitale, especialista en discursos golpistas en América del Sur, discursividad política y de los servicios de inteligencia. Ha publicado, por EUDEBA, la editorial de la Universidad de Buenos Aires, su libro ¿Cómo pudo suceder? Prensa escrita y golpismo en la Argentina (1930-1976), además de innumerables artículos en revistas científicas.

En esta entrevista, exploramos la trayectoria académica de María Alejandra Vitale. Conversamos inicialmente sobre su formación universitaria, tratamos luego su significativa participación en sociedades científicas de retórica, argumentación y discurso, y abordamos, por último, sus proyectos de investigación en la Universidad de Buenos Aires y en la Agencia Nacional de Promoción Científica y Tecnológica. Al respecto, consideramos temáticas de interés público como la representación que la prensa nacional hizo de las dictaduras argentinas del siglo $\mathrm{XX}$, así como diferentes estudios discursivos sobre los informes de inteligencia generados por los servicios de inteligencia de las Provincias de Buenos Aires y Santa Fe. También conversamos sobre la noción de memoria retórico-argumental y sobre la relación entre ethos e kairos, aportes teóricos que han contribuido fuertemente para los estudios de retórica, argumentación y discurso en la Argentina y en América Latina.

¡Esperamos que disfruten de la lectura!

EID\&A: En primer lugar, es un placer poder entrevistar a una profesora e investigadora tan activa e importante en la Argentina y también en América Latina. ¡Muchas gracias por haber aceptado nuestra invitación! Alejandra, querríamos comenzar hablando sobre tu formación académica, más allá de lo que figura en tu curriculum vitae. Hiciste tu carrera de grado y tu doctorado en la Universidad de Buenos Aires, tu tema de investigación fue el discurso y la argumentación de la prensa nacional sobre los golpes de Estado en la Argentina a lo largo del siglo XX. ¿Cuándo, cómo y con quién fue tu primer contacto con los estudios de retórica y argumentación? ¿Qué se estudiaba en la Argentina sobre argumentación en el período en que eras estudiante? 
Alejandra Vitale: Una parte de mis estudios de grado en la carrera de Letras en la Facultad de Filosofía y Letras de la Universidad de Buenos Aires la desarrollé durante la última dictadura militar de Argentina (1976-1983). Por esa razón, cualquier perspectiva que analizara el lenguaje en sus usos contextualizados y permitiera reflexionar sobre sus relaciones con la vida político-social estaba censurada. Los estudios clásicos, por su parte, se limitaban a la enseñanza de una gramática descontextualizada del griego y del latín. En consecuencia, el estudio de la retórica y de la argumentación estaban excluidos de la Universidad. Fue a partir de 1983, con la restauración de la democracia y la paulatina (re)construcción del pluralismo, que la retórica y la argumentación pudieron hacerse un paulatino espacio en las aulas. En los estudios clásicos, ello sucedió con la figura de dos notables profesores, antes proscriptos, que marcaron la época de la posdictadura: Ramón Alcalde, quien reintrodujo temas de retórica en los cursos de griego antiguo, y Eduardo Prieto, quien tomó una medida similar en los programas de Latín. En este sentido, podemos afirmar que el caso de Argentina confirma el tópico presente en Tácito, en su Diálogo de los oradores, según el cual por falta de actividad política la retórica entra en decadencia. Este mismo tópico fue reformulado por Michel Meyer (2008), cuando en sus Principia Rhetorica, sostiene que la Retórica renace cuando los dogmas se desmoronan, y por Marc Angenot (2008), quien vincula el retorno triunfal de la retórica con la crisis de los Grandes Relatos y el desencanto de las religiones seculares o políticas.

La democratización de la Universidad de Buenos Aires a partir de 1983 implicó la modificación de los planes de estudio y la apertura de concursos públicos para ocupar cargos de profesores. En la carrera de Letras y en el Ciclo Básico Común, que es el primer año de cursada en la Universidad de Buenos Aires, se introdujeron contenidos sobre análisis del discurso y argumentación. En mi caso, mi contacto con el campo fue en el marco de mi práctica docente en ese primer año de la Universidad de Buenos Aires, cuando publiqué el libro La argumentación. Una aproximación retórico-discursiva (REALE; VITALE, 1995), en colaboración con una colega de aquel momento, pensado en primer lugar, aunque no exclusivamente, como bibliografía para los alumnos y las alumnas. Ya entonces se aprecia mi interés en vincular el estudio de la argumentación con el de la ideología, en especial al hacer dialogar la Nueva Retórica de Perelman con nociones de análisis del discurso de tendencia francesa, como la de formación discursiva. Algo similar plantea el libro para el estudio de la organización del discurso argumentativo, al conectar la perspectiva de Marc Angenot sobre el discurso entimemático con el estudio de los conectores argumentativos. 
EID\&A: Considerando que las temáticas que elige para investigar dicen algo del investigador, ¿nos podrías decir cuáles fueron tus motivaciones para estudiar los discursos sobre las dictaduras argentinas, tanto en el período en que eras estudiante como en tu condición actual de líder del grupo de investigación GIAR (Grupo de Investigación en Archivos de la Represión) ${ }^{1}$ ?

Alejandra Vitale: Cuando debía entrar a la Escuela Media, quise hacer el examen de ingreso al Colegio Nacional Buenos Aires, prestigiosa institución que depende de la Universidad de Buenos Aires. Mi familia no me dejó, porque eran tiempos de dictadura y temían que me involucrara en política y pudiera terminar desaparecida. De hecho, muchos estudiantes del Colegio Nacional Buenos Aires desaparecieron durante la última dictadura militar. Terminé asistiendo a un colegio de monjas, exclusivo para mujeres. El ambiente era espantoso, retrógrado, represivo y prodictatorial. Las profesoras argumentaban a favor del golpe militar que derrocó a la presidenta constitucional Isabel Perón y contra la llamada "subversión".

La alianza de sectores de la Iglesia Católica argentina con las fuerzas armadas y el ambiente de censura y represión fue así un proceso histórico que experimenté en la vida cotidiana de mi propia adolescencia y que no olvidé más. Pienso que esto incidió, consciente o inconscientemente, en que muchos años después eligiera como tema de mi tesis de doctorado el análisis de las estrategias argumentativas que usó la prensa escrita argentina para justificar los golpes de Estado y las prácticas represivas. En efecto, en mi investigación doctoral descubrí que en ciertos sectores golpistas uno de los tópicos más usados para justificar los golpes militares fue el que denominé, siguiendo al historiador Loris Zanatta, el mito de la nación católica. Este mito postula como criterio de legitimidad de un gobierno no el mandato popular expresado en el sufragio, sino la búsqueda del bien común acorde a la implementación de los principios de la doctrina cristiana. De esta manera, el mito de la nación católica difumina los límites entre la Iglesia y el Estado y promueve la instauración de un Estado católico, tarea que la Iglesia delega en el Ejército, institución que junto con la Iglesia misma constituiría las bases de la nacionalidad, de las que son guardianas las fuerzas armadas. A su vez, este mito estableció una relación interdiscursiva con la Doctrina de la Seguridad Nacional, que concibió la defensa del cristianismo como un freno contra el avance del comunismo.

A propósito de mis investigaciones sobre el discurso de los servicios de inteligencia, recuerdo que la Maestría en Historia y Memoria, dictada en la Universidad Nacional de La Plata, me invitó a dar una conferencia sobre las estrategias que la prensa escrita argentina desplegó para argumentar a favor de los golpes de Estado durante el período

\footnotetext{
1 Grupo de Investigación en Archivos de la Represión: https://grupoinvestigacionarchivosdelarepresion.wordpress.com
} 
1930-1976. El aula donde se desarrolló la conferencia está ubicada en la Comisión Provincial por la Memoria y en ese contexto me enteré de que esta Comisión tiene a su cargo el resguardo del archivo de la Dirección de Inteligencia de la Policía de la Provincia de Buenos Aires (DIPBA), servicio de inteligencia policial abierto en 1956 y cerrado en 1998. Inmediatamente advertí que no existían investigaciones previas que desde el marco del análisis del discurso y la retórica estudiaran ese tipo de archivos, conocidos como "archivos de la represión". Y comprendí también que al estudiarlos daría continuidad a mi interés en analizar discursos autoritarios producidos en muchos casos en coyunturas dictatoriales o cuasiconstitucionales, para lo que ya tenía un insumo importante de mis investigaciones previas y de lecturas provenientes de la historiografía, la ciencia política y la sociología.

EID\&A: ¿De qué manera tus estudios actuales sobre los "archivos de la represión” y los servicios de inteligencia se relacionan con tus primeras investigaciones sobre el discurso golpista de la prensa escrita argentina? ¿Qué aportes realizan a los estudios de retórica, argumentación y discurso?

Alejandra Vitale: Un punto de contacto importante es la caracterización de los discursos y las estrategias que han legitimado y fueron condición de posibilidad de prácticas represivas, autoritarias, y de regímenes dictatoriales o cuasiconstitucionales. Se trata de desmontar los mecanismos retóricos y argumentativos que tendieron a hacerlos aceptables, tanto en el ámbito público a través de la prensa escrita como en el espacio secreto de los servicios de inteligencia. En este sentido, pienso que el discurso académico también es constructor de memorias e interviene a su manera en los debates sobre ellas, por lo que las dos investigaciones, desde una perspectiva interdisciplinaria, son pertinentes para el campo llamado Estudios de Memoria (JELIN, 2002).

En cuanto a los aportes de las investigaciones sobre los archivos de la represión, han enriquecido la noción de comunidad discursiva de Maingueneau a partir de considerar a los grupos productores de estos archivos como comunidades discursivas. Al respecto, el GIAR constató que un organismo de inteligencia como la DIPBA, que tenía una sede central en la ciudad de La Plata y delegaciones en diversos pueblos de la Provincia de Buenos Aires, construye distintas escenografías enunciativas y relaciones con otros servicios de inteligencia, por ejemplo, la Secretaría de Inteligencia del Estado (SIDE). Estos datos llevaron a problematizar cierta concepción homogeneizante y esencialista que se desprende de la noción de comunidad discursiva de D. Maingueneau. Al mismo tiempo, pensé la heterogeneidad propia de las comunidades discursivas a partir de las 
propuestas de J-L. Nancy $^{2}$ y R. Esposito ${ }^{3}$ para proponer la noción de relaciones intercomunitarias. Al respecto, puede sostenerse que las comunidades discursivas no poseen una identidad positiva o característica esencial que las constituya, sino que en las relaciones intercomunitarias adquieren sus rasgos identitarios y esto constituye un proceso abierto en su historicidad. Las investigaciones permitieron también plantear que las comunidades discursivas pueden ser pensadas como comunidades afectivas, en el sentido en que están reguladas -mediante normas, estereotipos y valores- las emociones legítimas e ilegítimas, los objetos o personas a los que pueden o no estar dirigidas y cuáles son los medios aceptables para expresarlas. Asimismo, sostengo que las comunidades discursivas constituyen comunidades argumentativas que delimitan el campo de lo argumentable y se caracterizan por cierta lógica argumentativa y la recurrencia de ciertos esquemas persuasivos. Estos recursos argumentativos, usados por ejemplo a los fines de legitimar la censura y el control cultural, están muy bien explicados en un libro reciente de dos integrantes del GIAR que dirigí en sus Maestrías y dirijo en sus doctorados, Paulina Bettendorff y Nicolás Chiavarino: Censura y control cultural en Argentina. Literatura, teatro, cine.

Al estudiar no solamente la dimensión verbal sino también icónica y multimodal de la discursividad de los archivos de la represión, he planteado que a una comunidad discursiva le es inherente determinado régimen escópico (JAY, 2003), un particular comportamiento de la percepción visual que entraña determinado verosímil de lo visible. Al respecto y en relación también con la problemática de la memoria discursiva, postulo que una misma matriz semiodiscursiva inherente a una comunidad discursiva regula la memoria tanto en su dimensión verbal como visual. Entiendo por matriz semiodiscursiva a las condiciones de posibilidad de los enunciados en materialidades significantes diversas; a las reglas generadoras de la producción enunciativa de una comunidad discursiva. De esta manera, me refiero a una memoria verbovisual que colabora a cohesionar a una comunidad discursiva y a legitimar sus propias prácticas.

EID\&A: A lo largo de tu trayectoria académica, dirigiste otros proyectos de investigación, más allá de los dos sobre archivos de la represión. ¿Podrías contarnos sobre sus temáticas, motivaciones, hipótesis iniciales, dificultades encontradas y principales resultados obtenidos?

Alejandra Vitale: Destaco el proyecto de colaboración entre el Ministerio de Ciencia y Tecnología de la Argentina con el National Research Fundation de la República de

\footnotetext{
2 Véase: La comunidad inoperante (LOM/Arcis, 2000); La comunidad desobrada (Arena Libros, 2001); La comunidad descalificada (Avarigani, 2015); La comunidad revocada (Mardulce, 2016).

3 Véase: Communitas - Origen y destino de la comunidade (Amorrortu editores, 2003); Comunidad, inmunidad, biopolítica (Herder Editorial, 2009).
} 
Sudáfrica, titulado "Discursos fundacionales e identidades nacionales en Argentina y Sudáfrica", codirigido con Philippe-Joseph Salazar, de la University of Cape Town. El proyecto propuso una investigación comparativa de los discursos fundacionales que estructuran la identidad nacional en la Argentina y Sudáfrica durante el periodo 19121994. En el marco de la crítica retórica y retomando el análisis del discurso, el objetivo fue doble: identificar y caracterizar un amplio conjunto de discursos clave que sirvieran al estudio de los principios discursivos de dos sociedades políticas ubicadas en el Atlántico Sur y contribuir a los estudios internacionales sobre la "retoricidad" de la formación de la identidad nacional y la denominada "retórica constitutiva". En este sentido, el proyecto enriqueció el campo de los estudios retóricos y del discurso en la Argentina a partir del conocimiento y la difusión de una línea de estudios retóricos hasta el momento aquí ignorada: la constitutive rhetoric. El término "retórica constitutiva" fue acuñado por James Boyd White (1985) con referencia a la capacidad del lenguaje para crear la identidad colectiva de una audiencia. Fue retomado y difundido por el académico canadiense Maurice Charland (1986), quien focaliza la noción de identificación como término clave para la retórica. Esta noción permite repensar el efecto retórico a la vez que rechaza la idea de un sujeto trascendental que ocuparía el lugar de la audiencia, que existiría antes, de modo independiente del discurso. La idea central de la retórica constitutiva según Charland es que las audiencias existen por el discurso, en el sentido en que son construidas por él, lo que implica examinar como efecto retórico lo que $\mathrm{L}$. Althusser ubica como el proceso clave de la ideología: la constitución de un sujeto. Charland analiza así la construcción retórica del pueblo quebequense; en el grupo argentino del proyecto, estudiamos la construcción retórica del pueblo argentino y consideramos como discursos fundacionales el que pronunció Juan Domingo Perón el 17 de octubre de 1945 y el que impartió Raúl Ricardo Alfonsín el 10 de diciembre de 1983. Se trata de dos discursos que, cada uno en su contexto de producción y de diferentes modos, son nodales en la constitución retórica de la audiencia con la identidad de pueblo argentino.

Por otra parte, el proyecto ha abordado una retórica pronunciada por mujeres y una retórica que hemos llamado "desde abajo", dado que la formación de la identidad nacional se basa también en formas retóricas con frecuencia autogeneradas y no reguladas de antemano. En esta línea fueron estudiados ciertos discursos de Eva Perón, como el que anuncia el voto femenino, que resulta fundacional porque instaura, por primera vez, un nuevo destinatario: interpela políticamente a la mujer y a todas las mujeres. Eva Perón construye una conciencia cívica, pero mantiene la condición insustituible que le corresponde como "columna básica del hogar", es decir, el espacio simbólico que se genera en sus discursos incorpora a la mujer en la escena política sin perder de vista los valores espirituales ni los roles de género tradicionalmente asignados. También el grupo argentino ha considerado como discurso fundacional el 
que Hebe de Bonafini pronunció en la última Marcha de la Resistencia de las Madres de la Plaza de Mayo bajo la dictadura militar, pues es constitutivo de un nuevo sujeto político en la democracia.

Por último, el proyecto planteó estudiar un tercer grupo de discursos que abarca un fenómeno que es fundamental para los imaginarios y las identidades nacionales: el papel de la Iglesia. La retórica religiosa es una característica perdurable de los imaginarios nacionales de la Argentina y Sudáfrica, no como un fenómeno eclesiástico (predicación a los fieles) sino como agente convincente para el compromiso social y político. En ambas sociedades, la retórica religiosa afecta a muchos niveles de la población y se articula a momentos críticos de la historia política. La investigación iba a centrarse en especial en la renovación teológica y su incidencia en la deliberación pública, con el Movimiento de Sacerdotes para el Tercer Mundo en la Argentina y la figura de Monseñor Tutu en Sudáfrica, de gran peso en la lucha contra el apartheid. Sin embargo, el Ministerio de Ciencia y Tecnología de Argentina no depositó los fondos de la última etapa del proyecto y este eje quedó inconcluso. De allí que la dificultad mayor con la que se haya enfrentado este proyecto haya sido la del financiamiento.

EID\&A: Alejandra, vamos a cambiar un poco de tema ahora. Además de ser participante activa de sociedades científicas, también fuiste presidenta y cofundadora de algunas de ellas, como la Asociación Argentina de Retórica, la Asociación Latinoamericana de Retórica y la Organización Iberoamericana de Retórica. Habiendo estado al frente de esas asociaciones, ¿nos podrías contar cuáles fueron las principales conquistas que promovieron y cuáles serían, en tu opinión, los principales desafíos a futuro para continuar con el impulso y la promoción de los estudios de Retórica, Argumentación y Discurso en el mundo académico latinoamericano?

Alejandra Vitale: Las asociaciones de retórica del ámbito latinoamericano e iberoamericano han difundido y consolidado los estudios retóricos en la región, han generado y profundizado lazos académicos entre las diversas universidades y han fortalecido los vínculos con sociedades de retórica de otros espacios, incluidos Estados Unidos, Europa y China. Estas sociedades científicas han estrechado el diálogo entre los especialistas en retórica y argumentación que provienen de los estudios de la antigüedad greco-romana y de otras perspectivas, como el análisis del discurso, la semiótica y la pragmática. Este intercambio enriquece nuevas y originales entradas teórico-metodológicas para los textos antiguos a la vez que el conocimiento y comprensión de la retórica antigua en quienes se dedican a la retórica y discursividad contemporáneas. Asimismo, ha favorecido la conformación de equipos de investigación interdisciplinarios. 
Otro logro es la creación de revistas que ocupan un espacio antes vacante, como la revista Rétor (www.revistaretor.org), de la Asociación Argentina de Retórica, la revista Metáfora. Revista de Literatura y Análisis del Discurso (www.metaforarevista.com), de la Asociación Peruana de Retórica, y la Revista Española de Retórica, de la Sociedad Española, de próxima aparición. Estas publicaciones electrónicas permiten dar a conocer e incentivar los conocimientos producidos, en especial, en América Latina, España y Portugal, en el campo de la retórica y la argumentación, así como el incremento de las citas bibliográficas mutuas entre académicos y académicas latino e iberoamericanos/as. También se han establecido y afianzado encuentros científicos periódicos en diversos países de América Latina y se han promovido nuevos posgrados, por ejemplo, la Maestría en Retórica y Argumentación, de la Universidad Nacional de Tucumán en Argentina, de la que soy codirectora.

Hasta el momento, existen asociaciones de retórica en Argentina, Brasil, Chile, Colombia, Bolivia, Perú, Cuba y México. Aspiramos a que se creen nuevas asociaciones en otros países de la región, así como a que se abran otros posgrados en Retórica y Argumentación. Ya existe la red de Retórica Jurídica coordinada por el profesor mexicano Gerardo Ramírez Vidal y esperamos que se abran nuevas redes con otras temáticas y problemáticas. Asimismo, vamos a incentivar la transferencia a diversos sectores de la sociedad, lo que se ha iniciado en México respecto del sistema judicial.

EID\&A: Cuando repasamos el conjunto de tu obra (tesis, libros, artículos, conferencias), advertimos que tu proyecto teórico busca articular el análisis del discurso con la retórica y la argumentación, para, principalmente, elaborar la noción de memoria retóricaargumental, que permite comprender la dimensión argumentativa de la memoria discursiva. ¿Nos podrías decir cuáles fueron -o son aún- los principales desafíos de articular las teorías del discurso y las teorías de la argumentación?

Alejandra Vitale: En efecto, para estudiar la dimensión argumentativa de las memorias discursivas acuñé el término "memoria retórico-argumental" con referencia al retorno y reformulación, en una serie discursiva, de estrategias persuasivas que buscan la adhesión en torno a cierta tesis. Estas estrategias persuasivas están integradas por los tópicos, el ethos y la construcción del pasado, tal como explico en mi libro ¿Cómo pudo suceder? Prensa escrita y golpismo en Argentina (1930-1976). He planteado luego que el pathos también forma parte de la memoria retórico- argumental (VITALE, 2020).

El término "memoria retórico-argumental" remite a una perspectiva retórica de estudio de la argumentación, que al ser articulada con la perspectiva francesa de análisis del discurso necesita reformular la concepción de sujeto que subyace en la retórica. En efecto, el sujeto de la retórica es similar al de la pragmática, y por ello es un sujeto intencional, portador de elecciones y decisiones, dueño del sentido de sus enunciados; 
un sujeto que despliega de modo consciente estrategias para alcanzar determinada finalidad. Es sabido que para Pêcheux ese sujeto es una ilusión y se ubica en lo que llama la "forma-sujeto". La zona de constitución de la subjetividad es, sin embargo, inaccesible para el sujeto y está ligada al inconsciente y a la ideología, que -como señala L. Althusser- constituye a los individuos en sujeto por medio de la interpelación.

Tanto la tradición retórica como la Nueva Retórica de Ch. Perelman son ajenas al materialismo histórico y el psicoanálisis, fundamentales para la teoría del discurso de Pêcheux. En el caso de Perelman, se constituye en el marco del liberalismo político que valora el pluralismo como condición indispensable para la convivencia pacífica entre quienes piensan diferente. De esta forma, la noción de lucha de clases, central en la propuesta de Pêcheux, se opone a la idea de lo razonable de Perelman, cuyo horizonte es el consenso. Porque si bien Perelman admite la relatividad, la pluralidad de lo razonable no se extiende a una perspectiva de sociedad en la que las relaciones de poder, la divergencia de intereses y las profundas diferencias ideológicas hacen del conflicto y agon el motor de la democracia.

A partir de considerar esas marcadas diferencias, he planteado que las memorias retórico-argumentales son propias a determinadas posiciones ideológicas que delimitan posiciones de sujeto. Los sujetos enunciadores al identificarse con esas posiciones de sujeto producen en la actualidad de un acontecimiento discursivo las estrategias retóricas que integran las memorias retórico-argumentales. De esta manera, la defensa de ciertas tesis o su rechazo y los medios para justificarlas o refutarlas, las estrategias persuasivas que retornan y se reformulan en una serie discursiva, de mediana o larga duración, son propias de determinadas posiciones ideológicas y de las posiciones de subjetividad que ellas configuran.

Las memorias retórico-argumentales son así matrices de producción de estrategias retóricas y de sentidos, que instituyen tanto lo que puede o no ser dicho y los modos de decirlo para un sujeto que no es completamente amo de su decir, dado que se establece como tal al identificarse con una posición de subjetividad delimitada por una ideología a la que le es inherente una memoria retórico-argumental. La ideología es aquí pensada como las relaciones que todo discurso entabla con sus condiciones materiales de posibilidad, en las que las luchas por el establecimiento y la reproducción de relaciones de poder, o la resistencia a ellas, ocupan un lugar central. Por ello las memorias retóricoargumentales no son espacios cerrados, estables ni homogéneos, sino que presentan fronteras difusas e inestables caracterizadas por lazos de alianza o de contradicción. 
EID\&A: ¿Cuál es el provecho que una investigación puede obtener, en términos de análisis, al convocar la noción de memoria retórico-argumental?

Alejandra Vitale: En primer lugar, la noción de memoria retórico-argumental permite analizar el funcionamiento de la memoria discursiva en términos argumentativos, comprender que el retorno de lo ya dicho y de los modos de decir del pasado en una nueva coyuntura tienen la función de generar o acrecentar la adhesión de cierta tesis. Es importante considerar el discurso en su historicidad, por ello al analizar esta dimensión argumentativa de las memorias discursivas es preciso contemplar las mutaciones del sentido y de las propias estrategias, lo que se ubica tanto en el plano del enunciado como en el de la enunciación. Estas mutaciones están ocasionadas por la incidencia de las diversas coyunturas históricas en que vuelve la memoria retóricoargumental. Por ello la noción de memoria retórico-argumental permite indagar cómo intervienen en la palabra argumentativa no sólo el tiempo breve del acontecimiento, sino, como hizo la Escuela de los Annales en su momento, la larga duración, o, al menos, un tiempo medio que excede la fugacidad acontecimental. Al respecto, me gusta parafrasear una frase de Marx del 18 Brumario para afirmar que el discurso y las argumentaciones de todas las generaciones muertas oprime como una pesadilla el cerebro de los vivos.

Por otra parte, la noción de memoria retórico-argumental permite explicar el parentesco argumentativo entre los discursos de diversos países ante acontecimientos históricos similares o subsumibles a procesos que los abarcan. Estudié, por ejemplo, de modo comparativo el caso de los discursos golpistas de la Argentina, Brasil y Uruguay. ¿Cómo explicar el aire de familia entre los discursos golpistas de 1964 en Brasil, los de 1973 en Uruguay y los de la Argentina de 1966 y 1976 y de todos estos con los discursos golpistas previos de este país durante el período 1930-1976? La noción de memoria retórico-argumental contribuye a esta explicación.

Las memorias retórico-argumentales, por último, permiten analizar la heterogeneidad constitutiva característica de toda palabra persuasiva, en la que lo ya dicho es retomado, a la vez que reformulado, en una nueva coyuntura, para persuadir a un auditorio particular.

EID\&A: Tus investigaciones han utilizado también la noción de ethos. Considerando el boom que esa noción tuvo desde 1987 con los trabajos de Maingueneau, tenemos algunas preguntas puntuales: ¿en que medida la noción de ethos no tiende a concentrarse en lo subjetivo y a perder de vista una dimensión estructural y crítica de lo ideológico? Además, ¿los estudios sobre ethos ya alcanzaron un umbral de saturación o todavía existen preguntas que deban ser respondidas? Si así fuese, ¿qué más puede investigarse al respecto? 
Alejandra Vitale: Pienso que no necesariamente el estudio del ethos lleva a perder de vista una dimensión estructural y crítica de lo ideológico. En sus primeras reflexiones sobre el ethos, Maingueneau (1987) lo considera una de las dimensiones de las formaciones discursivas y por ello articulado con la ideología. En mis propias propuestas sobre el ethos como una estrategia persuasiva que forma parte de la memoria retóricoargumental también lo he vinculado con la ideología y el eje del interdiscurso. En esta misma línea, he planteado (VITALE, 2018) que todo ethos está atravesado tanto por el kairos como por una posición de subjetividad delimitada por una formación discursiva. Para la retórica, el kairos es la articulación de los objetivos del orador con el tiempo, el lugar y las circunstancias del auditorio al que se dirige, dentro de un proceso que tiene como finalidad la producción de un discurso conveniente (prepô), que combine con armonía la forma y el contenido. El kairos está ligado así a la singularidad de una situación retórica específica, al aquí y ahora de una enunciación, lo que desde el análisis del discurso puede ser pensado con la noción de acontecimiento discursivo. Al mismo tiempo, todo ethos constituye una de las dimensiones de una formación discursiva, implica un sujeto de saber como posición de subjetividad, lo que se vincula con la noción de estructura e interdiscurso y con el eje de la repetición, de la regularidad. Ilustré esta propuesta con discursos de la ex presidente argentina Cristina Fernández de Kirchner, en los que se identifica, por un lado, un ethos pedagógico y experto, vinculado con el kairos y el aquí y ahora de la enunciación, pues se relaciona con el hecho de que es la primera mujer presidente electa que debe construir una identidad que la asocie a la vez que diferencie de su marido y ex presidente Néstor Kirchner; y por otro lado, un ethos guerrero y antiinstitucionalista, ligado interdiscursivamente a una formación discursiva propia de una ideología populista.

En relación con nuevas preguntas e investigaciones sobre el ethos, el ethos colectivo y su construcción es una línea que aún puede dar resultados interesantes, en particular en lo que se puede llamar, usando el término acuñado por una tesista cuyo doctorado dirijo (Laura Bonilla Neira), un ethos colectivo digital. En efecto, escrutar cómo las redes sociales inciden en la conformación de colectivos y sus consiguientes identidades es una tarea fructífera. También lo es profundizar la investigación en lo que se ha llamado el ethos femenino, en particular en la discursividad política. En las investigaciones del GIAR sobre archivos de la represión, hemos indagado en la identidad discursiva de los agentes de inteligencia, tal como se encontrará en el libro de próxima publicación que edité para la editorial EUDEBA: Rutinas del mal. Estudios discursivos sobre archivos de la represión. Sería interesante hacer estudios contrastivos con la conformación del ethos de agentes de inteligencia de otros países de Sudamérica en archivos de la represión que también se han abierto a la consulta pública. 
EID\&A: Pensando en una interfaz con la semiótica, ¿qué nos podrías decir sobre cómo abordar las múltiples dimensiones del sentido (la puesta en escena, el cuerpo, lo visual), a partir de una perspectiva argumentativa o retórica?

Alejandra Vitale: En primer lugar, destaco la actualidad de la tradición retórica. Se sabe que los gestos y la entonación que acompañan a la manifestación pública del discurso fueron estudiados por lo que la antigua retórica denominó Actio. Aristóteles en su Retórica le dedicó muy poco espacio en la primera parte del Libro III y focalizó la voz por sobre los gestos. Cicerón, en cambio, en su De Oratore pondera la Actio como parte fundamental de la Retórica, a la que le ofrece un segmento más extenso que Aristóteles; sin embargo, coincide con él en prestarle mayor atención a la voz que al gesto. La Actio gana mucho mayor protagonismo en las Instituciones Oratorias de Quintiliano, quien se refiere a ella en todo un capítulo del Libro Undécimo. Sin embargo, en Quintiliano la voz asimismo tiene primacía por sobre el gesto, dado que anuncia que se dedicará primero a la voz que al ademán, porque todo afecto penetra el alma por los oídos y el gesto se acomoda a la voz. En los tres autores se pondera así la voz por sobre el gesto y, también, en los tres la Actio es vinculada con las pasiones. Ello involucra al pathos, a las emociones despertadas en el auditorio, pero también al ethos, en cuanto la voz y el gesto expresan las emociones experimentadas o fingidas por el orador.

En mi caso, me he interesado por la potencia retórica de un gesto muy denso semióticamente, la risa/sonrisa, y en específico en el discurso político presidencial de Cristina Fernández de Kirchner (VITALE, 2014). La sonrisa que acompaña a un enunciado verbal tiene las características que G. Calbris (2003) le asigna a los gestos coverbales: son signos eminentemente contextuales, convencionales, motivados y polisémicos, que cumplen las mismas funciones comunicativas que los signos verbales.

Desde el campo de la retórica, M. S. Celentano (1995) diferencia entre la risa/sonrisa ajena a la agresión y a las relaciones jerárquicas (como la de alegría, bienvenida, etc.) y la risa/sonrisa que involucra la agresión y la jerarquía (como la de burla, desprecio, victoria, etc.) y que supone generalmente alguien que se ríe con el emisor y un tercero, que es objeto de la risa/sonrisa. En el marco del análisis del discurso, M. Sandré (2011) distingue entre la risa/sonrisa con efecto consensual y la risa/sonrisa con efecto de disenso. Por otra parte, aborda la risa/sonrisa en cuanto produce un efecto capaz de intervenir en la interpretación del discurso: se trata de un efecto atenuador o, por el contrario, un efecto amplificador y un efecto revelador de un sentimiento particular.

En el caso de la sonrisa de Cristina Fernández de Kirchner aparecen los dos tipos de sonrisa. Por un lado, una sonrisa no agresiva que acompaña la informalidad de sus alocuciones o la violación del protocolo y que tiene como único destinatario a quien se ríe junto con ella. Por otra parte, una sonrisa burlona con una cuota de agresión que no sólo incluye a quien se ríe con ella sino al tercero que provoca la sonrisa, el antagonista 
político, con el que la presidente argentina polemiza. En ambos casos, podría afirmarse que la sonrisa tiene un efecto amplificador, sea de informalidad o de polemicidad de lo dicho.

Respecto del estudio de la argumentación en materialidades significantes diversas, nos remite al campo de discusión sobre la argumentación multimodal, de mucho peso en los medios digitales y en las redes sociales. Se enfatizaron las imágenes visuales y algunos les negaron la posibilidad de argumentar, alegando que son ambiguas y vagas, que no pueden reducirse a proposiciones y que apelan más a las emociones que a la razón. Sin embargo, tres perspectivas importantes han ponderado el análisis de la argumentación multimodal. La pragmadialéctica se interesó por ella, por ejemplo, en anuncios, carteles, películas y dibujos animados. En este sentido, L. Groarke (1970) defendió la posición de que las imágenes argumentan, sosteniendo que una imagen que expresa un punto de vista con premisas de apoyo es una imagen argumentativa.

En la perspectiva retórica, J. A. Blair (2004) sostiene que hay argumentación visual si lo que se comunica incluye un factor que puede considerarse una razón para aceptar una proposición, cambiar de actitud o realizar una acción. Esto se prueba traduciendo verbalmente lo que se comunica visualmente. La argumentación visual, sin embargo, en comparación con la argumentación verbal, se caracteriza por su falta de sutileza, por su sencillez y por la imposibilidad de entrar en refutaciones y contraargumentaciones.

Finalmente, el Análisis Crítico del Discurso considera que los signos que se manifiestan de diferentes formas -los recursos semióticos que se dan simultáneamente en los discursos, como la imagen visual, la posición espacial, el sonido, entre otros- son seleccionados y organizados de acuerdo con los intereses, a partir de los cuales se producen los signos. En este sentido, se postula que los signos están motivados en su relación entre forma y significado. La argumentación se concibe como persuasión y los estudios se centran en la lectura crítica de mensajes multimodales que discriminan a las minorías o legitiman relaciones desiguales de poder.

El campo de la argumentación multimodal es actualmente muy rico y en permanente reconfiguración, como lo demuestra en Brasil el reciente número monográfico de la Revista de ABRALIN (n. 20, v. 3, 2021).

EID\&A: Teniendo en cuenta los estudios académicos en América Latina, ¿cuál es la agenda de investigación que debería ser priorizada para el desarrollo futuro de los estudios de Retórica, Argumentación y Discurso en la periferia del capital?

Alejandra Vitale: Una problemática que me parece importante es el estudio de la imbricación del discurso religioso y del discurso político desde una perspectiva crítica, porque se vincula con la importancia que tienen las Iglesias en las sociedades 
latinoamericanas y su llegada a sectores de la población con derechos vulnerados. También es para priorizar el análisis del discurso de las derechas, en muchos casos relacionados con el de las Iglesias, dado el avance que han tenido en el espacio electoral de muchos de nuestros países. Entender y desmontar sus lógicas retóricoargumentativas contribuirá a poder neutralizarlos y refutarlos en el espacio público con mayor eficacia. Algo similar sucede con los denominados "discursos del odio", aquellos que promueven o legitiman la discriminación y/o la violencia hacia una persona o un colectivo en función de la pertenencia a un grupo religioso, étnico, nacional, político, racial, de género o cualquier otra identidad social. Al mismo tiempo, considero que como las tramas discursivas del presente de nuestros países se tejen sobre las tramas de la memoria, es oportuno seguir indagando en las memorias de las dictaduras sudamericanas y en sus funciones en las discursividades actuales. En relación con esta agenda, pienso que la perspectiva contrastiva entres los países sudamericanos contribuirá a la integración tanto académica como política y al compromiso con sociedades más equitativas y menos violentas.

\section{Referências}

ANGENOT, Marc. Dialogues de sourds. Traité de rhétorique antilogique. Paris: Mille et une Nuits, 2008

BLAIR, John Anthony. The Rhetoric of Visual Arguments. In: HILL, Charles; HELMERS, Marguerite (eds). Defining Visual Rhetorics. Mahwah: Lawrence Erlabaum, 2004. p. 4161.

CALBRIS, Geneviève. L'expression gestuelle de la pensée d'un homme politique. Paris, CNRS Éditions, 2003.

CELENTANO, Maria Silvana. Comicità, umorismo e arte oratoria nella teoria retorica antica. Eikasmos. Quaderni Bolognesi di Filologia Classica, VI, p. 162-174, 1995.

CHARLAND, Maurice. Constitutive Rhetoric. Quarterly Journal of Speech, n. 73, v. 2, p. 133-150, 1986.

GROARKE, Leo. Toward a Pragma-Dialectics of Visual Argument. In: Van EEMEREN, Frans H. (ed.). Advances in Pragma-Dialectics. Amsterdam: Sic Sat, 2002. p. 137-151.

JAY, Martin. Regímenes escópicos de la modernidade. In: Campos de fuerza. Entre la historia intelectual y la crítica cultural. Buenos Aires: Paidos, 2003.

JELIN, Elizabeth. Los trabajos de la memoria. Buenos Aires: Siglo XXI, 2002.

MAINGUENEAU, Dominique. Nouvelles tendance en analyse du discours. Paris: Hachette, 1987.

MEYER, Michel. Principia Rhetorica. Une théorie générale de l'argumentation. Paris: Fayard, 2008. 
REALE, Analía; VITALE, Alejandra. La argumentación. Una aproximación retóricodiscursiva. Buenos Aires: Ars, 1995.

SANDRÉ, Marion. Mimiques et politique. Analyse des rires et sourires dans le débat télévisé. Mots. Les langages du politique, n. 96, p. 13-27, 2011

VITALE, María Alejandra. El ethos en la 'conversacionalización' del discurso público. Las alocuciones de asunción de la presidente argentina Cristina Fernández de Kirchner. Langage et Societé, Paris, n. 149, p. 49-67, 2014.

VITALE, María Alejandra. El èthos: entre el kairós y las formaciones discursivas. Estudios del Discurso, Cuernavaca, n. 4, v. 1, p. 36-50, 2018.

VITALE, María Alejandra. Memoria retórico-argumental y pathos. Revista Verbum, São Paulo, n. 9, v. 1, p. 254-268, 2020.

WHITE, James Boyd. Heracles' Bow. Madison: University of Wisconsin, 1985. 